\title{
The European Radiological Data Exchange Platform (EURDEP): 25 years of monitoring data exchange
}

\author{
Marco Sangiorgi $^{1}$, Miguel Angel Hernández-Ceballos ${ }^{1}$, Kevin Jackson ${ }^{2}$, Giorgia Cinelli ${ }^{1}$, \\ Konstantins Bogucarskis ${ }^{1}$, Luca De Felice ${ }^{1}$, Andrei Patrascu ${ }^{1}$, and Marc De Cort ${ }^{1}$ \\ ${ }^{1}$ European Commission, Joint Research Centre (JRC), Ispra, Italy \\ ${ }^{2}$ European Commission, Directorate-General for Energy (DG ENER), Luxembourg, Luxembourg
}

Correspondence: Marco Sangiorgi (marco.sangiorgi@ec.europa.eu)

Received: 25 July 2019 - Discussion started: 16 September 2019

Revised: 26 November 2019 - Accepted: 11 December 2019 - Published: 21 January 2020

\begin{abstract}
During the early phase of an accident with the release of radioactive material to the environment at the local or transboundary scale, a rapid and continuous system of information exchange, including realtime monitoring data to competent authorities and the public, is critical for setting up countermeasures. This information and data exchange must be carried out in a harmonized and consistent manner to facilitate its interpretation and analysis. After the Chernobyl accident in 1986, and in order to avoid the competent authorities being unprepared again for a similar event, the European Commission (EC) defined and put in place a directive (Council Decision 87/600/EURATOM, 1987) which essentially obliges a member state that decides to implement widespread countermeasures to protect its population to notify the European Commission without delay. The same Council Decision also specifies that the results of radiological monitoring must be made available to the European Commission and all potentially affected member states. Over the past 30 years, the European Commission has invested resources in developing and improving a complete system to carry out this delicate task, currently composed of two platforms: the European Community Urgent Radiological Information Exchange (ECURIE) and the European Radiological Data Exchange Platform (EURDEP). This paper aims to increase knowledge of the latter system as a valuable tool for understanding and analysing the radioactivity levels in Europe. Commencing with background information, in this paper, we will describe the EURDEP system in detail, with an emphasis on its status, data availability, and how these data are diffused depending on the audience. Within the scope of this publication, we describe an example of measurements available in the EURDEP system, which to be used for scientific purposes. We provide two complete datasets (air-concentration samples - https://doi.org/10.2905/23CBC7C4-4FCC-47D5-A286-F8A4EDC8215F; De Cort et al., 2019a; and gamma dose rates - https://doi.org/10.2905/0F9F3E2D-C8D7-4F46-BBE7-EACF3EED1560; De Cort et al., 2019b) for the recent radiological release of ${ }^{106} \mathrm{Ru}$ in Europe, which occurred between the end of September and early October 2017. Records stored are publicly accessible through an unrestricted repository called COLLECTION belonging to the JRC Data Public Catalogue (https://data.jrc.ec.europa.eu, last access: 1 July 2019).
\end{abstract}




\section{Introduction}

The severe accident that occurred at the Chernobyl Nuclear Power Plant (NPP) on 26 April 1986 led to a large release of radioactivity to the environment, and large areas of the Europe were contaminated, as can be seen, for example, in the Chernobyl ${ }^{137}$ Cs Atlas of Europe (De Cort et al., 1998). Following this accident, many lessons were learned in dealing with nuclear emergency preparedness and response as well as the need to raise awareness of the causes of accidents and to document the lessons that can be learned (IAEA, 2005). Among the lessons learned from Chernobyl accident, the large transboundary effects of the radioactive release clearly emphasized the need to establish and support high-level national and international emergency response systems; in particular, countries felt the need to set up activities with a view of significantly improving the exchange of information including monitoring data. The exchange of this information in the early phase of a nuclear or radiological (hereafter R/N) event, and preferably in real time, allows competent authorities to be more effective in taking timely and appropriate health and environmental countermeasures to radiation. Besides this, this accident and its consequences also led to a large resurgence in radioecological studies aimed at improving remediation and the ability to make predictions on the post-accident situation, all in recognition that more knowledge was required to cope effectively with potential future accidents (e.g. Alexakhin and Geras'kin, 2011; Beresford et al., 2016).

Over the past 30 years, the European Commission (EC) has invested in improving the rapid exchange of information and data during R/N emergencies (De Cort et al., 2011). In 1987, and in order to avoid the authorities being as unprepared for future accidents of a similar scale, the EC defined and put in place a directive (Council Decision 87/600/EURATOM, 1987) which essentially obliges a country that decides to implement widespread measures for the protection of its population to notify the EC without delay. The resulting early notification system was named the European Community Urgent Radiological Information Exchange (ECURIE). The same Council Decision also specifies that results of radiological monitoring be exchanged. The resulting mechanism for this task was named the European Radiological Data Exchange Platform (EURDEP; https://remon.jrc.ec.europa.eu/, last access: 1 July 2019), which was launched in 1994 and is nowadays managed by the EC Joint Research Centre (JRC) located in Ispra (Italy) as part of their support programme to the Directorate-General for Energy (DG ENER). In a platform-wide or European context the EURDEP system does not have a primary alerting role. The notification of a radiological accident or emergency is accomplished through the early notification system ECURIE. Therefore, no action may be taken based on EURDEP data without prior consultation with the data provider. The clear concept behind EURDEP is to better equip the decision makers with current and continuous information available in the form of real-time monitoring data to aid in the definition of the most appropriate countermeasures. The EURDEP system is mainly used for the continuous exchange and storage of gamma dose-rate (hereafter GDR) values, and, due to its importance in the case of emergency, air-concentration levels. In fact, for a remote source term, as was the case with the Fukushima NPP accident for Europe, radioactivity levels in air can only be measured by high- and medium-volume air samplers, since activity concentrations are far too low to produce a detectable rise in the external gamma dose rate (Bossew et al., 2012). Meteorological data, though to a lesser degree, are also exchanged and stored.

Keen interest and high motivation for EURDEP have promoted continuous growth since its creation. Beginning with six countries exchanging monitoring data from about 300 stations in various national data formats by e-mail once per week in 1985, EURDEP has evolved to its current state, with 39 countries capable of exchanging real-time monitoring information collected from more than 5500 automatic surveillance systems (up to once per hour during an emergency) in a standard data format through secure ftp and web services. Such a large-scale harmonized data-exchange system for radioactivity measurements is unique in the world. Figure 1 shows the progress of participation in the EURDEP network from 1996 to 2019. It is worth mentioning that the participation in EURDEP for European Union member states is mandatory, and the exchange of off-site monitoring data during a radiological accident is an official obligation as required under the $87 / 600$ Council Decision. Participation of non-EU countries in EURDEP is voluntary but then, in most cases, subject to a country-specific memorandum of understanding (MoU).

This paper aims to increase knowledge regarding the existence of the EURDEP system as a valuable medium, which can be used for better understanding and analysing radioactivity levels in Europe. Within the scope of this publication, we aim at describing the unique collection of measurements stored in the EURDEP system since 2002 and at providing access to relevant datasets to the scientific community. While many of the data have previously been used for various purposes within refereed or scientific applications (e.g. Bossew et al., 2012, 2017; Szegvary et al., 2007), complete datasets for specific radiological events (e.g. De Cort et al., 2019a, b) have never been integrally published. In the case of a radiological event, this extensive network collects and publishes valuable information to be potentially used for scientific purposes, such as verification of models of source term evaluation and reconstruction, documentation of temporal and spatial evolution of radioactivity, etc. This information is also useful for people studying risks associated to planned and unplanned releases and for testing models that require spatial data. An example of a dataset within the EURDEP system is the recent ${ }^{106} \mathrm{Ru}$ release detected in Europe in SeptemberOctober 2017 (Bossew et al., 2019). In the present paper, we 


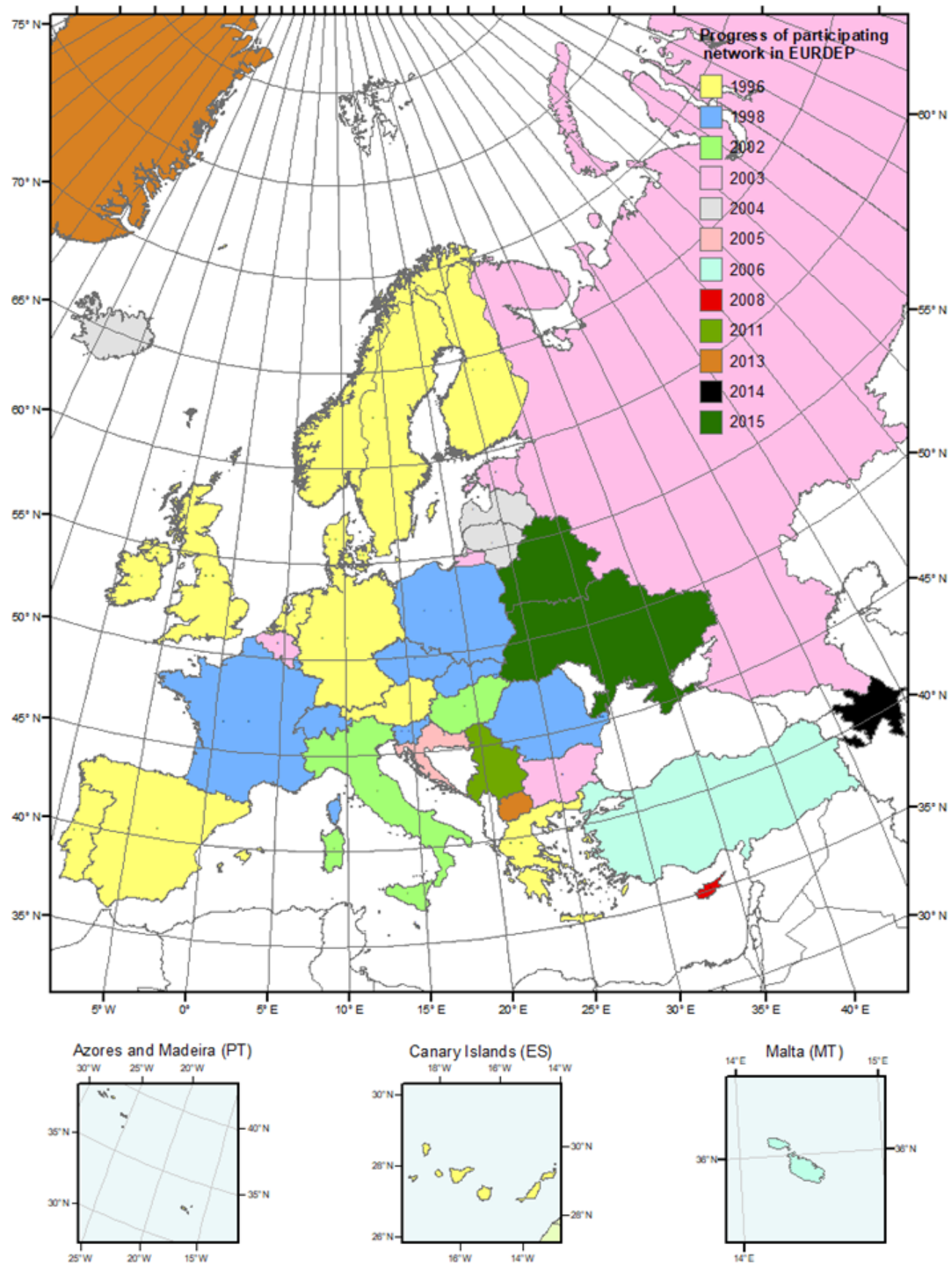

Figure 1. Progress of participating networks in EURDEP. The 40 networks in 2019 are composed of 38 European countries' networks plus Canada (since 2013) and the Decommissioning and Waste Management (DWM) JRC stations located in Ispra, Italy (since 2008). JRC network is operated by EC staff because it is part of EC territory although located in Italy.

explain how to get access to the full subset of GDR and air samples stored during that period in the EURDEP system.

Section 2 describes the EURDEP monitoring network, while Sect. 3 focuses on EURDEP data as well as the applied quality control methodology. Section 4 describes the method of exchanging data via the EURDEP system and how data are made accessible to different audiences, while Sect. 5 presents the data which are available on EURDEP for the $2017{ }^{106} \mathrm{Ru}$ release detected in Europe. Finally, conclusions are reported in Sect. 6. 


\section{EURDEP networks}

The Chernobyl accident resulted in increased radioactivity levels over most of Europe (e.g. Evangeliou et al., 2016). Although several European countries had, by 1986, already developed automatic monitoring networks and in some cases had established bilateral agreements for the exchange of this information, the magnitude of the Chernobyl accident (e.g. Steinhauser et al., 2014) demonstrated the need to extend such schemes to the continental scale. Subsequent to the accident, many additional countries set up GDR-based automatic monitoring networks for delineating the radioactive cloud and, in parallel, decided to, without legal obligations, participate in the international data-exchange mechanism EURDEP in order to benefit from the availability of Europe-wide measurements during both routines and emergencies. GDR networks have rather disparate station locations due to differences in the design of national networks. Such differences are in general a consequence of national approaches and policies. The design of the topology of a GDRmonitoring network can be based on several factors, such as threat analyses, the enlargement of the area to be monitored, the density of the population, and the geological topography of the covered area. In addition, the purpose of the network (alert function only or other functions) and its required technical performance (e.g. spatial resolution) are factors which have an effect on the location of the monitoring sites. As can be seen in Fig. 2, countries apply some of the following considerations when siting their monitoring stations:

- Monitoring stations are placed to form a regular grid covering the entire country.

- Monitoring stations are mostly placed at the border of the country, frequently used by countries which do not have national facilities which may cause a radiological release.

- Monitoring stations are mostly placed around sites at risk, i.e. around NPPs.

- Monitoring stations are mostly placed in the surrounding of the most densely populated areas, following the logic that this layout caters to more accurately gauged countermeasures for the local population.

In the early stages of EURDEP development, only ADR (ambient dose rate) measurements were exchanged, but over the years other sample types were added. The Fukushima accident showed once more the importance of air-concentration data and also - as experienced in Europe - that only HVASs (high-volume air samplers) are capable of measuring the extremely low level of contaminants in the air caused by a distant accident. More modern air-concentration sampling stations are fully automated, online, and connected to the national data centres so that the data reach EURDEP with minimum delay. Most of air sampling stations, however, are of- fline, their filters are manually replaced once or twice per week, and the measurements are then carried out in laboratories; in this case, the delay with which air-concentration data from these stations are available on EURDEP can be more than a week. To reduce costs and to make nuclidespecific data available more quickly, a few European countries have begun using spectrometric probes. Although the sensitivity of this type of probe is much lower than a HVAS station, they can give very valuable results during a local emergency where a higher level of contaminants may occur. As of February 2019, 14 countries exchange nuclide-specific data, and, among them, Switzerland, Cyprus, the Czech Republic, Germany, Estonia, Finland, Hungary, Norway, and Lithuania regularly send air-concentration data, which are of utmost importance during an accident.

\section{EURDEP data}

The existence of the EURDEP platform has contributed significantly to the harmonization of the data format and procedures related to the collection of measured radioactivity in Europe in the last 2 decades. The EURDEP format allows indicating, for each measurement, whether the data are nonverified (NV), verified (V), or non-plausible (NP). Because the system allows changing this attribute by "overwriting" already submitted measurements and/or by editing single measurements via the restricted website, the data providers can send data even before they are verified so as to have the latest measurements available to all users with the minimum possible delay. Hence, most of the measurements presented on the restricted website are non-verified data, which means that meteorological conditions such as heavy rain or snow, or defects in the instruments, electronics, or software, can result in deviations from the true value. Consequently, isolated seemingly alarming levels on the map cannot automatically be taken as an indication of increased levels of radioactivity. Even if several nearby stations show such increased values, it does not necessarily imply an actual increase in radiation levels. Some data providers verify the data and then update the measurements with the "verified" attribute, while other data providers prefer to leave the data as NV in the system and only to delete or update measurements that did not pass the national verification controls.

\subsection{Ambient dose rate}

ADR measurements (expressed in $\mathrm{nSvh}^{-1}$ ) are crucial for carrying out an accurate evaluation of external exposure to human bodies after an accidental or intentional release of radionuclide, as an enhanced external exposure to the population can only partly be assessed from the increase in the measured external net dose rate in a first step (e.g. Sono et al., 2005). Nowadays, EURDEP allows the exchange of the ADR data from more than 5000 online monitoring stations in Europe (Fig. 2). Most countries send their data within $2 \mathrm{~h}$ 


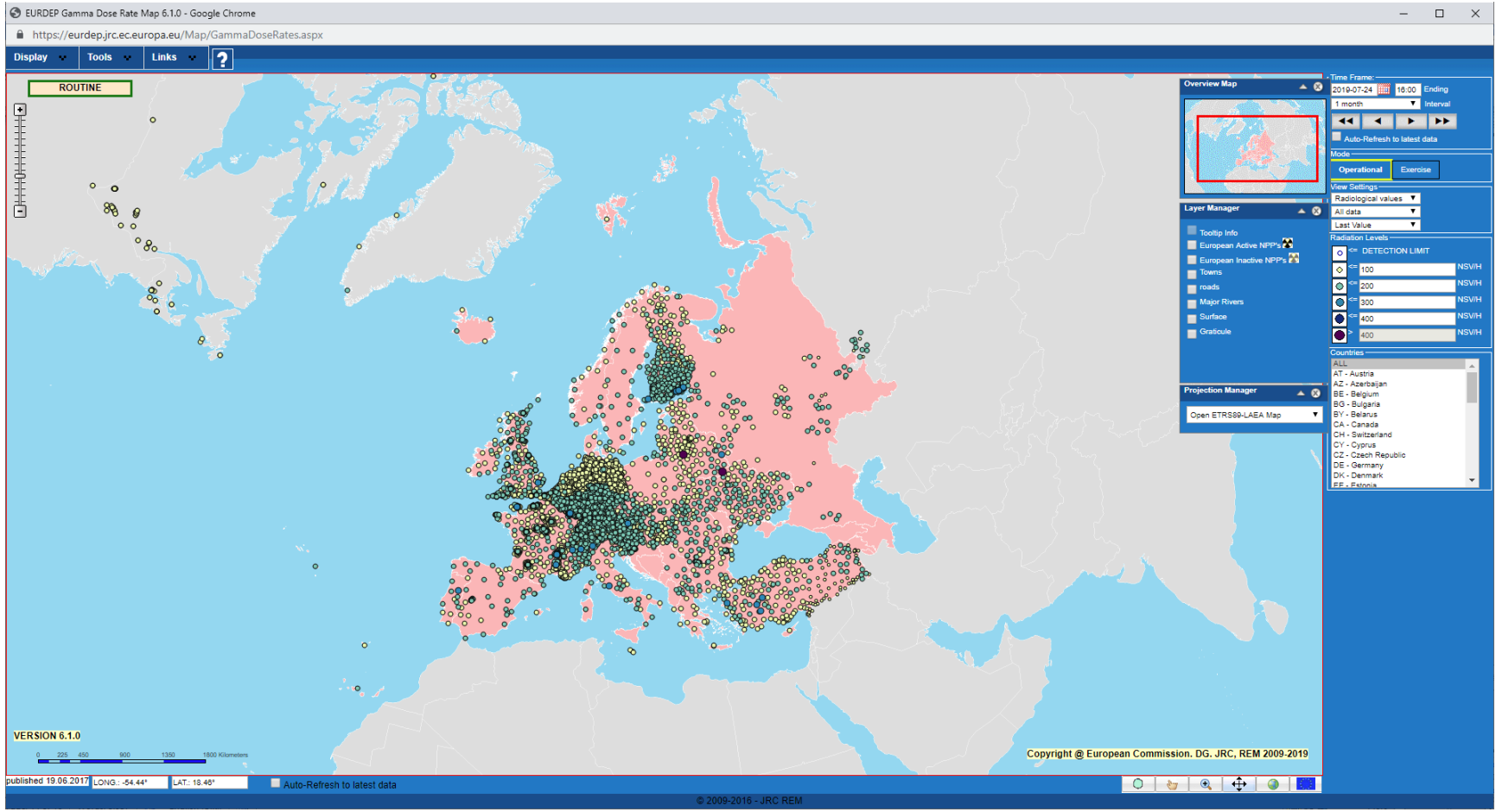

Figure 2. Screenshot of the EURDEP "expert map" showing the locations of the gamma-dose-rate-monitoring stations (Copyright $\odot$ European Commission. DG. JRC, REM 2009-2019).

of the measurement, both during routines and emergencies, while some countries send data as a routine on a daily basis, but without any delay during an emergency.

An ideal site for ADR monitoring stations is on extensive flat grassland on natural undisturbed ground, with no obstacles in a circle of at least $20 \mathrm{~m}$ at minimum, and at the height of $1 \mathrm{~m}$ above the ground. In this sense, the way in which a detector is installed strongly influences its readings (e.g. installing on a wall or a roof in town can give considerably different results from the same probe). In addition, the height above mean sea level of the station, different background levels, and probe characteristics such as the self-effect contribute to differences in the exchanged measurements that are not relevant to the real radiological situation (e.g. Bossew et al., 2017). In this sense, the availability of the station properties allows a better evaluation of the measurements and estimating the artificial contribution to the ADR, in the case of a $\mathrm{R} / \mathrm{N}$ event, by subtracting self-effect, cosmic radiation, and terrestrial background from the reported measurement.

For the purpose of ADR data harmonization, it is worth mentioning projects such as AIRDOS, MetroERM (http:// earlywarning-emrp.eu/, last access: 1 July 2019), EGNRSWG, and INTERCAL (Schauinsland, BfS). The EURDEP system was upgraded in the past years by the so-called AIRDOS extension (Bossew et al., 2007), which provided detailed information on European dose-rate-monitoring networks focusing on probe characteristics, e.g. the sensitivity and other physical properties. Each station description contains various and sometimes in a very detailed way, characteristics of the probe and the station. This way, corrections in row data can be done at the EURDEP system in a consistent manner using the probe and station properties. The German BfS developed a simplified site characteristic correction that would allow for strongly reducing the measurement deviations caused by the site-specific effects (Stöhlker et al., 2019). It is planned to implement this simplified site characteristic correction in a future EURDEP website version so that users can optionally select a view that applies this correction method to obtain better inter-comparability of the measurements.

\subsection{Air concentrations}

The impact in Europe of the Fukushima accident, although air concentrations remained far below levels which could have caused radiological concern (Bossew et al., 2012), showed the importance of being able to measure the extremely low level of contaminants in the air, caused by either far-away or small-scale accidents. Since 2015, EURDEP stakeholders consider the exchange of air-concentration data (samples) to be a high-priority item. The recent ${ }^{106} \mathrm{Ru}$ (Bossew et al., 2019) event has reinforced this need.

Air concentration data which are considered to be a priority during an accident and are routinely sent to EURDEP are ${ }^{131} \mathrm{I},{ }^{137} \mathrm{Cs},{ }^{134} \mathrm{Cs},{ }^{132} \mathrm{Te},{ }^{7} \mathrm{Be}\left({ }^{7} \mathrm{Be}\right.$ for comparison 
purposes), ${ }^{212} \mathrm{~Pb}$, and ${ }^{214} \mathrm{~Pb}$ measurements $\left(\mathrm{Bq} \mathrm{m}^{-3}\right)$. These nuclide concentrations are transmitted both during routines and emergencies, and the only difference between these two transmissions modality is the frequency with which such data are sent. Thanks to this improved output, the EURDEP system increases its reliability to track very low levels of radioactivity and contribute to reducing public concern in Europe.

EURDEP also contains data of total-beta radiation $\left(\mathrm{Bq} \mathrm{m}^{-3}\right)$. Currently, there are only 100 stations carrying out this type of measurement. Total-beta measurements are available, excluding those related to external radiation.

\subsection{Meteorological data}

During the years, meteorological data were added to the exchange within the EURDEP system. Weather parameters influence the radiological levels; e.g. atmospheric pressure, snow, and rain can change the amount of radon that is released from the soil, and rain can be the cause of higher readings because of radon wash-out effects, while wind strength and direction can help in estimating where and how fast aerosols will move (e.g. Bossew et al., 2017). The scope of this exchange of meteorological information is therefore to facilitate the interpretation of the radiological values, both during routines and emergencies, and to better understand if an increased radioactivity level is caused by natural or artificial events. To this purpose, information about pressure, temperature, wind direction, wind-speed, precipitation, precipitation occurrence, precipitation duration, precipitation intensity, relative humidity, and solar radiation is exchanged through the EURDEP system. However, not all countries deliver this kind of data yet. Countries that send meteorological data (status of February 2019) are the following: BG, BY, CY, CZ, FI, GR, HR, HU, IE, IT, MT, NO, PL, RO, RS, and SI. It is worth noting that the meteorological information transmitted through the network originates from the corresponding EURDEP monitoring station and not from a dedicated one.

\section{Exchange of EURDEP data and EURDEP maps}

\subsection{Data exchange}

All data exchanged via EURDEP are subjected to copyright of the original data provider and cannot be used for other purposes, including scientific research, without authorization.

There are two ways of exchanging radiological data in EURDEP. During routines, the monitoring data are made available by the participating organizations at least once a day, while during an N/R emergency, each organization makes data available at least once every $2 \mathrm{~h}$. In practice, more and more organizations make their national data available on an hourly basis both during routine and during emergency conditions.
An essential condition for exchanging and comparing data at the international level is the agreement about some common basic standards about data format and exchange protocols. All data under EURDEP are exchanged using standard formats and standard exchange protocols which are EURDEP proprietary, since the 2013 data format and transmission protocol is compliant with the requirements of the International Radiological Information Exchange (IRIX) format. The IRIX standard, which was developed jointly by the International Atomic Energy Agency (IAEA), the EC, and experts from the member states under an IAEA action plan, is the recommended means of exchanging information among emergency response organizations at national and international levels during a nuclear or radiological emergency (Mukhopadhyay et al., 2018). In 2014, in accordance with a $2010 \mathrm{MoU}$ between EC and IAEA which sought to establish a global radiological data-exchange system based on EURDEP, EURDEP started the submission of the European radiological data to the International Radiation Monitoring Information System (IRMIS, https://nucleus.iaea.org/Pages/ IRMIS.aspx, last access: 1 July 2019) under provisions given by the Emergency Notification and Assistance Convention (ENAC). In this way EURDEP assures the role of European Regional HUB for IRMIS. Initially IRMIS was supposed to be constructed on the basis of EURDEP, but it was not: IRMIS is currently a data collection tool with a website, while EURDEP is a data-exchange platform. IRIX was also developed to replace a data-exchange format called CIS (convention information structure) currently used by the ECURIE platform and the prompt notification system, ENAC, which belongs to IAEA.

Since the exchange of monitoring data at the international level plays a fundamental role during an emergency, it is obvious that high availability is a major asset. To address this target, EURDEP has been conceived with high redundancy. The EURDEP network has three central nodes, and each central node collects the monitoring data from all the national servers and makes it available, on ftp-servers, to all participants. The three nodes are located at the EC JRC in Ispra (Italy), the BfS in Freiburg (Germany), and the EC DG ENER (Directorate for Energy) in Luxembourg. The node at the JRC has a special function because it verifies all the data, loads them into a database, and makes them available for viewing and downloading through a web interface. All monitoring data are available and can hence be downloaded from these three sites.

\subsection{EURDEP maps}

As was stated in the Introduction, EURDEP is a tool for decision makers, providing notified and continuous real-time monitoring data to define the most appropriate countermeasures before a radioactive plume impacts the population. This fast and reliable availability of data is important because the radioactive plume can travel over large distances in a short 


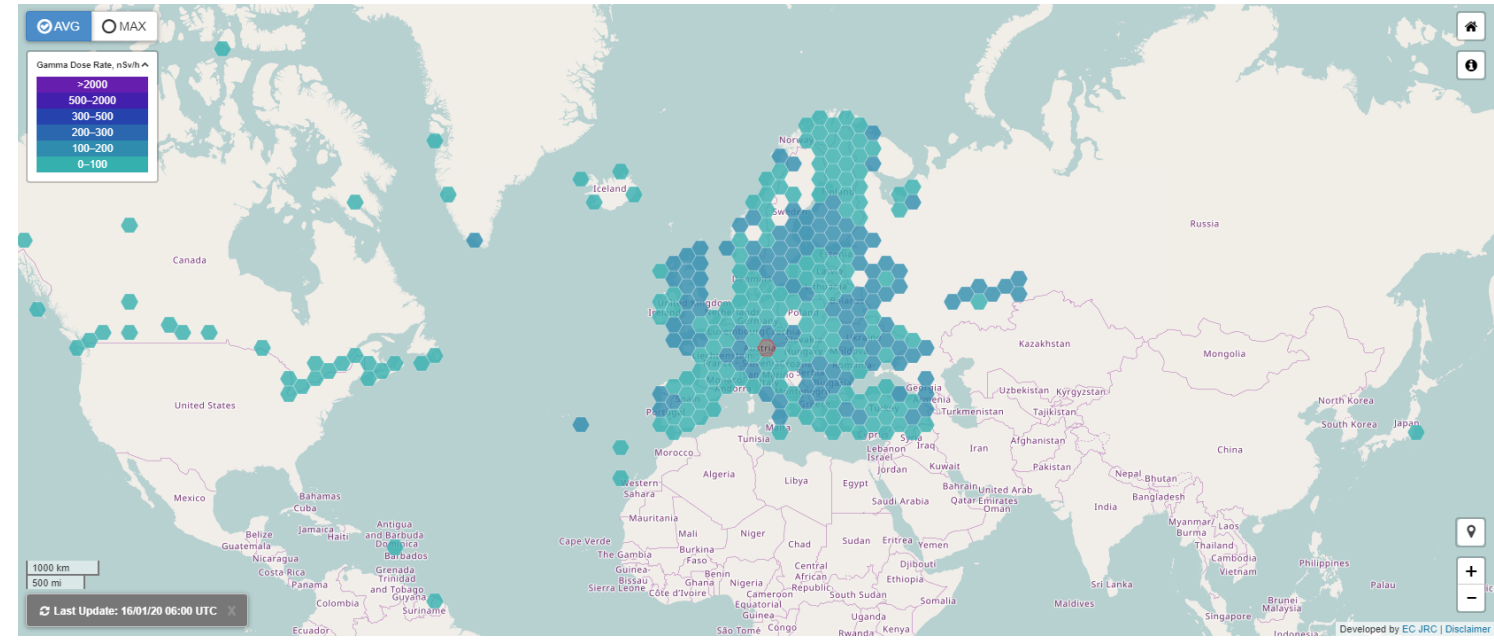

Figure 3. Screenshot of the EURDEP Public Map. This map shows the maximum and the average value of total gamma dose rate for each hexagon considering the stations inside, which have reported measurements during the last $24 \mathrm{~h}$, and considering values to be time-averaged values (@ EC JRC).

time and in any direction, depending on the meteorology during the accident (e.g. the dispersion of radionuclides worldwide from the Fukushima Daiichi Nuclear Power Plant; e.g. Povinec et al., 2013). To this purpose, the EURDEP Expert Map (restricted website) allows unlimited access to all monitoring data through various web services and other secure channels. This map allows downloading time series, which, in the case of an emergency, can be analysed to take the corresponding countermeasures to limit its impact on the population, and it has a role in confirming previous predictions and therefore the measures taken.

Nowadays, there is a growing concern with the public about the radioactivity levels, the potential risk of future nuclear accidents, and the recovery process in the aftermath of an accident (Sato and Lyamzina, 2018). In this context, and based on the Council Decision 87/600/EURATOM, which also specifies that monitoring data must be made available to the public, clear and transparent communication is carried out through the EURDEP platform. Most measurements of environmental radioactivity in the form of GDR aggregated averages and maxima for the last $24 \mathrm{~h}$ from some 5500 GDRs in 37 European countries are made available through the public freely accessible EURDEP website, which neither requires a license nor subscription (Fig. 3). This public EURDEP website is placed in the Radioactivity Environmental Monitoring (REM) group website (https://remon.jrc.ec. europa.eu/About, last access: 1 July 2019). The REM public website (https://remon.jrc.ec.europa.eu/, last access: 13 January 2020) provides a unique portal of access for all the data and products developed by the REM group at the JRC, such as the European Atlas of Natural Radiation (Cinelli et al., 2019). In addition, and to provide more detailed information to general public and scientists, EURDEP provides, to registered users, some extra applications, including net- works data submission statistics, i.e. stations reporting intervals and measurement types, which may help to explain various environmental radioactivity phenomena. These applications, however, may experience some malfunctioning due to its transition to a newer version, which is planned to become available in November 2019 and will offer more options in terms of configuration and filtering of environmental radioactivity.

\section{Data availability}

Accidents with involvement of radiation sources occur, although infrequently. The IAEA database of nuclear and radiological incidents can be consulted at http://www.laka.org/ docu/ines/ (last access: 1 July 2019) and includes a full list of nuclear and radiation incidents which have been reported since 1990 by national nuclear regulatory agencies to the IAEA. In addition, the IAEA database on unusual radiation events (RADEV) is intended, among others, to provide a repository of information on accidents, near misses, and any other unusual events involving radiation sources not directly involved in the production of nuclear power or its fuel cycle.

EURDEP data are collected and stored in the routine or emergency mode and constitute a valuable archive of radiological measurements potentially used for scientific purposes. We present here an example of two complete datasets referring to a radiological event that can be retrieved from the EURDEP database. The example chosen is the widespread detection of ${ }^{106} \mathrm{Ru}$ in Europe in 2017, which, however, had no radiological significance for the population. To point out the event, it is worth mentioning that ${ }^{106} \mathrm{Ru}$ had only been detected on the continental scale following the Chernobyl nuclear power plant accident. Between the end of September and early October 2017, several European networks involved 


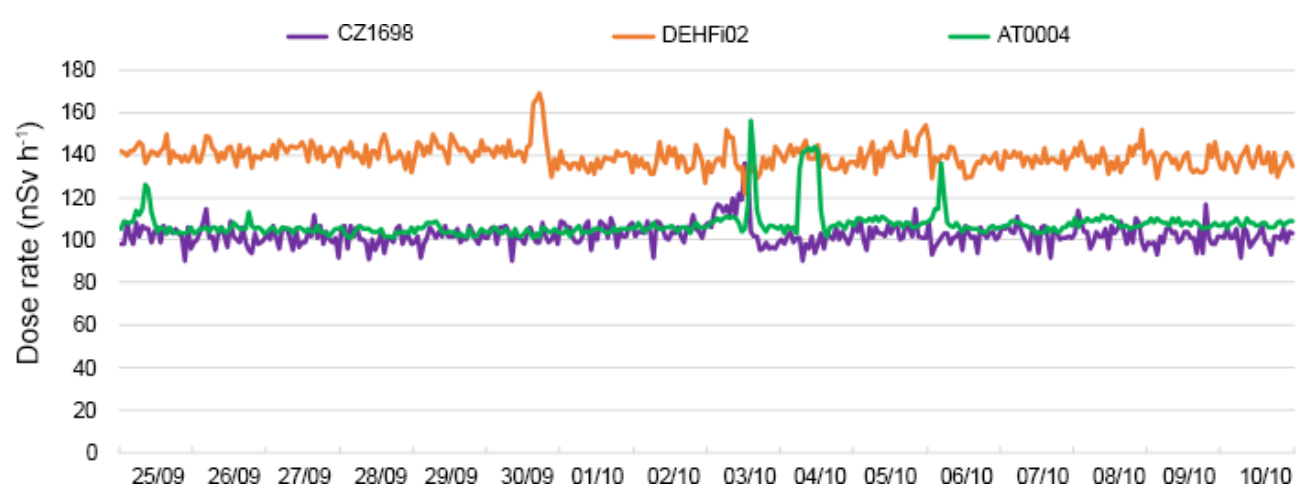

Figure 4. Time series (day and month of year 2017) of gamma dose rate recorded during the ${ }^{106}$ Ru event at three monitoring sites in Europe: one in Czech Republic (CZ1698), one in Germany (DEHFi02), and one in Austria (AT0004).

in the monitoring of atmospheric radioactive contamination recorded the presence of ${ }^{106} \mathrm{Ru}$ (Bossew et al., 2019; Masson et al., 2019). A possible origin for this ${ }^{106} \mathrm{Ru}$ inflow to the atmosphere from a ground-based source in the southern or central Urals is substantiated by Shershakov et al. (2019). Some regions of central and eastern Europe measured $1 \mathrm{~d}$ mean activity concentrations of up to 10 over $100 \mathrm{mBq} \mathrm{m}^{-3}$. Different values for dose conversion factor from activity concentration to air immersion effective dose (Eckermann and Rymann, 1993; Yoo et al., 2013; IAEA-TECDOC-1162, 2000) would lead to a gamma immersion dose rate far below radiological concern and, in addition, below detectability with the EURDEP dose-rate network (some $\mathrm{nSv} \mathrm{h}^{-1}$ ). For Budapest, as an example, Jakab et al. (2018) estimated an external dose from the radioactive plume (cloud shine) of $9 \times 10^{-8} \mathrm{mSv}$. Figure 4 shows the time series of gamma dose rate, recorded during the event at three measuring sites.

EURDEP data of the ${ }^{106} \mathrm{Ru}$ event are freely available for download at JRC Data Catalogue, while other datasets of interest may be made available on request. We invite interested people to regularly check the JRC Data Catalogue (https://data.jrc.ec.europa.eu, last access: 1 July 2019) for updates and get into contact with the authors for specific requests.

${ }^{106} \mathrm{Ru}$ event datasets (total gamma dose rate and sampling stations of air-concentration activity) can be downloaded individually as comma separated value (CSV) files and zipped due to their heavy size by following these subsequent persistent identifiers (PIDs):

- ${ }^{106} \mathrm{Ru}$ event (air-concentration samples) at https://doi.org/10.2905/23CBC7C4-4FCC-47D5A286-F8A4EDC8215F (De Cort et al., 2019a),

$$
\begin{gathered}
-{ }^{106} \mathrm{Ru} \text { (total gamma dose rates) } \\
\text { https://doi.org/10.2905/0F9F3E2D-C8D7-4F46- } \\
\text { BBE7-EACF3EED1560 (De Cort et al., 2019b). }
\end{gathered}
$$

The fields made available for download are the following, in the same order as specified hereafter.
- The fields made available for download for gamma dose rates are the following: two-letter country codes as supplied by the ISO (International Organization for Standardization), monitoring station identifier, locality identifier, longitude, latitude, date and time of the beginning of measurement (yyyy-mm-dd, hh:mm:ss), date and time of the end of measurement (yyyy-mm-dd, hh:mm:ss), and measurement value of the gamma dose rate (expressed as $\mathrm{nSv} \mathrm{h}^{-1}$ ).

- For air-concentration activity the fields are as follows: two-letter country codes as supplied by the ISO (International Organization for Standardization), sampling station identifier, locality identifier, longitude, latitude, sample category identifier radionuclide, measuring unit, date and time of beginning of sampling (yyyy-mm-dd, hh:mm:ss), date and time of end of sampling (yyyymm-dd, hh:mm:ss), and measurement value of concentration activity.

\section{Conclusions}

The JRC's European Radiological Data Exchange Platform (EURDEP) makes radiological monitoring data widely available from most European countries in near real time. EURDEP facilitates the transmission of large datasets from environmental radioactivity and emergency preparedness monitoring networks, as requested by EU legislation between national authorities and the European Commission. It is an integrated part of the official European Commission's radiological and nuclear emergency arrangements, which gather data from 40 networks in 38 European countries plus Canada, mainly through 5500 automatic stations. Even in the current situation, there is not perfect inter-comparability of the ADR data because of the use of different probes and different siting characteristics and monitoring station topologies, but the current degree of harmonization and the availability of the station characteristics allow a practical use of the Europewide data both in periods with and without events. 
Air-sample data communication is still scarce in comparison with ADR data. Currently, about 14 countries regularly report standard radionuclides $\left({ }^{131} \mathrm{I},{ }^{137} \mathrm{Cs},{ }^{7} \mathrm{Be}\right.$, etc.). The recent ${ }^{106} \mathrm{Ru}$ event over Europe, even with a very low radiological impact, raised the need to improve and increase the exchange of this information in order to deliver a fair picture of the situation and support to decision makers.

EURDEP development activities at the EC are expected to need considerable resources in the future because of a continuous expansion of data providers and exchanged sample types and nuclides, and it is necessary to keep up with the continuous developments of the large number of national systems which participate to EURDEP. Future work will focus on extending the number of participating countries, transmitting more on-site meteorological data, expanding to the whole spectrum of sample types foreseen by the Euratom Treaty, refining measurements by applying filters for various natural background components and, last but not least, globalizing the system in collaboration with the IAEA.

Author contributions. At the time of writing this paper, $\mathrm{KB}$ oversees EURDEP development and maintenance and is the main reference for information, being the person responsible of the project. MS and MAHC are the main authors, and GC and KJ were the main reviewers and gave technical guidance.

Competing interests. The authors declare that they have no conflict of interest.

Acknowledgements. We would like to acknowledge the work or the past 2 decades of the EEWG, without which the EURDEP platform would not have developed as it has.

Review statement. This paper was edited by Jens Klump and reviewed by two anonymous referees.

\section{References}

Alexakhin, R. A. and Geras'kin, S. A.: 25 years after the accident at the Chernobyl nuclear power plant: Radioecological lessons, Radioprotect., 46 S595-S600, https://doi.org/10.1051/radiopro/20116516s, 2011.

Beresford, N. A., Fesenko, S., Konoplev, A., Skuterud, L., Smith, J. T., and Voigt, G.: Thirty years after the Chernobyl accident: What lessons have we learnt?, J. Environ. Ra., 157, 77-89, https://doi.org/10.1016/j.jenvrad.2016.02.003, 2016.

Bossew, P., De Cort, M., Dubois, G., Stöhlker, U., Tollefsen, T., and Wätjen, U.: Evaluation of Existing Standards of Measurement of Ambient Dose Rate; and of Sampling, Sample Preparation and Measurement for Estimating Radioactivity Levels in Air, AA N_TREN/NUCL/S12.378241 JRC Ref. N_21894-200404 A1CO ISP BE, Download from the private section of EU-
RDEP, available at: https://eurdep.jrc.ec.europa.eu/Basic/Pages/ Private/Downloads/Default.aspx (last access: 20 January 2019), 2007.

Bossew, P., Kirchner, G., De Cort, M., De Vries, G., Nishev, A., and De Felice, L.: Radioactivity from Fukushima Dai-ichi in air over Europe; part 1: spatio-temporal analysis, J. Environ. Ra., 114, 22-34, https://doi.org/10.1016/j.jenvrad.2011.11.019, 2012.

Bossew, P., Cinelli, G., Hernández-Ceballos, M. A., Cernohlavek, N., Gruber, V., Dehandschutter, B., Bleher, M., Hellmann, I., Weiler, F., Tollefsen, T., Tognoli, P. V., and De Cort, M.: Estimating the terrestrial gamma dose rate by decomposition of the ambient dose equivalent rate, J. Environ. Ra., 166, 296-308, https://doi.org/10.1016/j.jenvrad.2016.02.013, 2017.

Bossew, P., Gering, F., Petermann, E., Hamburger, T., Katzlberger, C., Hernandez-Ceballos, M. A., De Cort, M., Gorzkiewicz, K., Kierepko, R., and Mietelski, J. W.: An episode of Ru-106 in air over Europe, September-October 2017 - Geographical distribution of inhalation dose over Europe, J. Environ. Ra., 205-206, 79-92 https://doi.org/10.1016/j.jenvrad.2019.05.004, 2019.

Cinelli, G., Tollefsen, T., Bossew, P., Gruber, V., Bogucarskis, K., De Felice, 1., and De Cort, M.: Digital version of the European Atlas of natural radiation, J. Environ. Ra., 196, 240-252, https://doi.org/10.1016/j.jenvrad.2018.02.008, 2019.

Council decision 87/600/Euratom of 14 December 1987 on Community arrangements for the early exchange of information in the event of a radiological emergency, ELI: available at: http: //data.europa.eu/eli/dec/1987/600/oj (last access: 1 July 2019), 1987.

De Cort, M., De Vries, G., Galmarini, S., and Tanner, V.: International data and information exchange in Europe - systems to assist the EU Member States in radiological and nuclear emergency situations, Radioprotection, 46, S751-S757, https://doi.org/10.1051/radiopro/20116881s, 2011.

De Cort, M., Bogucarskis, K., Patrascu, A., Sangiorgi, M., and Hernandez Ceballos, M. A.: Ruthenium-106 event (air concentration samples), European Commission Joint Research Centre (JRC) [Dataset], https://doi.org/10.2905/23CBC7C4-4FCC47D5-A286-F8A4EDC8215F, PID: available at: http://data. europa.eu/89h/23cbc7c4-4fcc-47d5-a286-f8a4edc8215f, last access: 1 July 2019a.

De Cort, M., Bogucarskis, K., Patrascu, A., Sangiorgi, M., and Hernandez Ceballos, M. A.: Ruthenium-106 event (total gamma dose rates), European Commission Joint Research Centre (JRC) [Dataset], https://doi.org/10.2905/0F9F3E2D-C8D74F46-BBE7-EACF3EED1560, PID: available at: http://data. europa.eu/89h/0f9f3e2d-c8d7-4f46-bbe7-eacf3eed1560, last access: 1 July $2019 b$.

De Cort, M., Dubois, G., Fridman, Sh. D., Germenchuk, M. G., Izrael, Yu. A., Janssens, A., Jones, A. R., Kelly, G. N., Kvasnikova, E. V., Matveenko, I. I., Nazarov, I. M., Pokumeiko, Yu. M., Sitak, V. A., Stukin, E. D., Tabachny, L. Ya., Tsaturov, Yu. S., and Avdyushin, S. I.: Atlas of caesium deposition on Europe after the Chernobyl accident, Office for Official Publications of the European Communities, EUR 16733, ISBN 92-828-3140-X, Catalogue number CG-NA-16-733-29-C, Luxembourg, 1998.

Eckermann, K. F. and Rymann, J. C.: External exposure to radionuclides in air, water and spil: Federal guidance reports 12, EPA-402-R-93-081, available at: https://www.epa.gov/sites/ 
production/files/2015-05/documents/402-r-93-081.pdf (last access: 25 July 2018), 1993.

Evangeliou, N., Hamburger, T., Talerko, N., Zibtsev, S., and Møller, A. P.: Reconstructing the Chernobyl Nuclear Power Plant (CNPP) accident 30 years after. A unique database of air concentration and deposition measurements over Europe, Environ. Pollut., 216, 408-418, https://doi.org/10.1016/j.envpol.2016.05.030, 2016.

IAEA-TECDOC-1162: Generic procedures for assessment and response during a radiological emergency, available at: https:// www-pub.iaea.org/mtcd/publications/pdf/te_1162_prn.pdf (last access: 22 August 2018), 2000.

International Atomic Energy Agency (IAEA): Proceedings of an International Conference on Chernobyl: Looking Back to go Forward. Organized by the International Atomic Energy Agency on behalf of the Chernobyl Forum and held in Vienna, 6-7 September 2005, ISBN 978-92-0-110807-4, 2005.

Jakab, D., Endrödi, G., Kocsonya, A., Pántya, A., Pázmándi, T., and Zagyvai, P.: Methods, results and dose consequences of $106 \mathrm{Ru}$ detection in the environment in Budapest, Hungary, J. Environ. Ra., 192, 543-550, https://doi.org/10.1016/j.jenvrad.2018.08.004, 2018.

Masson, O., Steinhauser, G., Zok, D., Saunier, O., Angelov, H., Babić, D., Bečková, V., Bieringer, J., Bruggeman, M., Burbidge, C. I., Conil, S.,Dalheimer, A., De Geer, L.-E., de Vismes Ott, A., Eleftheriadis, K.,Estier, S., Fischer, H., Garavaglia, M. G., Gasco Leonarte, C.,Gorzkiewicz, K., Hainz, D., Hoffman, I., Hýža, M., Isajenko, K.,Karhunen, T., Kastlander, J., Katzlberger, C., Kierepko, R., Knetsch, G.-J.,Kövendiné Kónyi, J., Lecomte, M., Mietelski, J. W., Min, P., Møller, B.,Nielsen, S. P., Nikolic, J., Nikolovska, L., Penev, I., Petrinec, B., Povinec, P. P.,Querfeld, R., Raimondi, O., Ransby, D., Ringer, W., Romanenko, O., Rusconi, R., Saey, P. R. J., Samsonov, V., Šilobritienè, B., Simion, E.,Söderström, C., Šoštarić, M., Steinkopff, T., Steinmann, P., Sýkora, I., Tabachnyi, L., Todorovic, D., Tomankiewicz, E., Tschiersch, J.,Tsibranski, R., Tzortzis, M., Ungar, K., Vidic, A., Weller, A., Wershofen, H.,Zagyvai, P., Zalewska, T., Zapata García, D., and Zorko, B.: Airborne concentrations and chemical considerations of radioactive ruthenium from an undeclared major nuclear release in 2017, P. Natl. Acad. Sci. USA, 116, 1675016759, https://doi.org/10.1073/pnas.1907571116, 2019.
Mukhopadhyay, S., Baciu, F., Saluja, G., Segarra, J., and A1binet, F.: Application of International Radiological Information Exchange (IRIX) standards for radiation monitoring data reporting, Proceedings Volume 10763, Radiation Detectors in Medicine, Industry, and National Security XIX; 1076308, https://doi.org/10.1117/12.2309380, 2018.

Povinec, P. P., Gera, M., Holý, K., Hirose, K., Lujaniené, G., Nakano, M., Plastino, W., Sýkora, I., Bartok, J., and Gažák, M.: Dispersion of Fukushima radionuclides in the global atmosphere and the ocean, Appl. Ra. Isotop., 81, 383-92, https://doi.org/10.1016/j.apradiso.2013.03.058, 2013.

Sato, A. and Lyamzina, Y.: Diversity of Concerns in Recovery after a Nuclear Accident: A Perspective from Fukushima, Int. J. Environ. Res. Publ. Health, 15, 350, https://doi.org/10.3390/ijerph15020350, 2018.

Shershakov, V. M., Borodin, R. V., and Tsaturov, Y. S.: Assessment of Possible Location Ru-106 Source in Russia in September-October 2017, Russ. Meteorol. Hydrol., 44, 196202, https://doi.org/10.3103/S1068373919030051, 2019.

Sono, H., Yanavisawa, H., Ohno, A., Kojima, T., and Soramasy, N.: Evaluation of Gamma-Ray Dose Components in Criticality Accident Situations, J. Nucl. Sci. Technol., 42, 678-687, https://doi.org/10.1080/18811248.2004.9726437, 2005.

Steinhauser, G., Brandl, A., and Johnson, T. E.: Comparison of the Chernobyl and Fukushima nuclear accidents: A review of the environmental impacts, Sci. Total Environ., 470-471, 800-817, https://doi.org/10.1016/j.scitotenv.2013.10.029, 2014.

Stöhlker, U., Bleher, M., Doll, H., Dombrowski, H., Harms, W., Hellmann, I., Luff, R., Prommer, B., Seifert, S., and Weiler, F.: The German dose date monitoring network and implemented data harmonization techniques, Ra. Protect. Dos., https://doi.org/10.1093/rpd/ncy154, 2019.

Szegvary, T., Conen, F., Stöhlker, U,.Dubois, G., Bossew, P., and de Vries, G.: Mapping terrestrial $\gamma$-dose rate in Europe based on routine monitoring data, Ra. Measure., 42, 1561-1572, https://doi.org/10.1016/j.radmeas.2007.09.002, 2007.

Yoo, S. J., Jang, H. K., Lee, J. K., Noh, S., and Cho, G.: External dose-rate conversion factors of radionuclides for air submersion, ground surface contamination and water immersion based on the new ICRP dosimetric setting, Ra. Protect. Dos., 156, 7-24, https://doi.org/10.1093/rpd/nct045, 2013. 